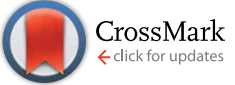

Cite this: RSC Adv., 2017, 7, 17244

Received 20th February 2017 Accepted 12th March 2017

DOI: 10.1039/c7ra02112g

rsc.li/rsc-advances

\section{Highly efficient red emission and multiple energy transfer properties of $\mathrm{Dy}^{3+} / \mathrm{Mn}^{4+}$ co-doped $\mathrm{Ca}_{14} \mathrm{Zn}_{6} \mathrm{Ga}_{10} \mathrm{O}_{35}$ phosphors}

\begin{abstract}
Yiyang Zhou, Weiren Zhao, ${ }^{*}$ Junhua Chen and Zifeng Liao
Novel $\mathrm{Dy}^{3+} / \mathrm{Mn}^{4+} \mathrm{co}$-doped $\mathrm{Ca}_{14} \mathrm{Zn}_{6} \mathrm{Ga}_{10} \mathrm{O}_{35}$ phosphors have been synthesized by a solid state reaction technique. Strong blue emission ranging from $370 \mathrm{~nm}$ to $500 \mathrm{~nm}$ was observed for the $\mathrm{Ca}_{14} \mathrm{Zn}_{6} \mathrm{Ga}_{10} \mathrm{O}_{35}$ host, attributed to the recombination of a donor-acceptor pair through a tunneling process. High internal and external quantum efficiencies of $64.4 \%$ and $56.2 \%$ respectively were obtained under the excitation of $310 \mathrm{~nm}$ in $\mathrm{Mn}^{4+}$ doped $\mathrm{Ca}_{14} \mathrm{Zn}_{6} \mathrm{Ga}_{10} \mathrm{O}_{35}$. This external quantum efficiency is the highest one reported for $\mathrm{Mn}^{4+}$ doped oxides. The temperature-dependent quantum efficiency of $\mathrm{Ca}_{14} \mathrm{Zn}_{6} \mathrm{Ga}_{10} \mathrm{O}_{35}: \mathrm{Mn}^{4+}$ is also measured, indicating the unchanged absorption of the excitation light with temperature. In $\mathrm{Ca}_{14} \mathrm{Zn}_{6} \mathrm{Ga}_{10} \mathrm{O}_{35}: \mathrm{Dy}^{3+}, \mathrm{Mn}^{4+}$ phosphors, multiple energy transfer from the host to $\mathrm{Dy}^{3+}$ and from $\mathrm{Dy}^{3+}$ to $\mathrm{Mn}^{4+}$ is observed and is confirmed to be a result of the dipole-dipole interaction. The emission changes from deep blue to white to deep red according to the different $\mathrm{Dy}^{3+} / \mathrm{Mn}^{4+}$ concentration ratio, and the warm white emission can be realized with the chromaticity coordinate (0.345, 0.275), CCT $3525 \mathrm{~K}$ and CRI 87. These results suggest that $\mathrm{Ca}_{14} \mathrm{Zn}_{6} \mathrm{Ga}_{10} \mathrm{O}_{35}: \mathrm{Mn}^{4+}$ phosphors have potential application as high efficiency red phosphors for solid-state lighting, while $\mathrm{Dy}^{3+} / \mathrm{Mn}^{4+} \mathrm{co}$-doped $\mathrm{Ca}_{14} \mathrm{Zn}_{6} \mathrm{Ga}_{10} \mathrm{O}_{35}$ phosphors can be used as a single-phased white phosphor.
\end{abstract}

\section{Introduction}

The $\mathrm{Mn}^{4+}$ ion, which is similar to the isoelectronic $\mathrm{Cr}^{3+}\left(\mathrm{d}^{3}\right)$, gives a rather complicated optical spectrum. It shows absorption in the whole ultraviolet region ${ }^{1,2}$ and the subsequently emitted phosphorescence is in the deep red $(620-720 \mathrm{~nm})$ due to transition from the ${ }^{2} \mathrm{E} \rightarrow{ }^{4} \mathrm{~A}_{2} \cdot{ }^{3,4}$ Thus, $\mathrm{Mn}^{4+}$-doped red phosphors might have potential application in lighting, ${ }^{5}$ holography, ${ }^{6}$ lasers, ${ }^{7}$ and dosimetry. ${ }^{8}$

As a kind of red phosphor with a high quantum efficiency, $\mathrm{Mn}^{4+}$ activated fluoride phosphors have attracted considerable interest. ${ }^{9} \mathrm{Mn}^{4+}$ doped $\mathrm{K}_{2} \mathrm{TiF}_{6}$ red phosphors show internal quantum yields as high as $98 \%$, and high performance white LEDs with $3556 \mathrm{~K}$ correlated color temperature, 81 color rendering index $\left(R_{\mathrm{a}}\right)$ and luminous efficacy of $116 \mathrm{~lm} \mathrm{~W}^{-1}$ have been fabricated with these red phosphors. ${ }^{10}$ Unfortunately, fluoride host is not stable because of their easy deliquescence. ${ }^{11}$ Moreover, the toxic HF solution is harmful to the environment in the synthesis process, which restricts its applications. Fluoride phosphors are also not suitable for fluorescent lamps because of their reactivity with the mercury vapor. ${ }^{12}$ Unlike fluoride phosphors, the $\mathrm{Mn}^{4+}$ activated oxide phosphors exhibit good chemical stability. ${ }^{13}$ However, the currently known $\mathrm{Mn}^{4+}$

School of Physics and Optoelectronic Engineering Guangdong University of Technology, Guangzhou 510006, China. E-mail: zwren123@126.com; Fax:+86020 39322265; Tel: +8602039322265 activated oxide phosphors cannot meet the needs of general lighting due to their low quantum efficiency. The internal quantum of $\mathrm{Sr}_{4} \mathrm{Al}_{14} \mathrm{O}_{25}: \mathrm{Mn}^{4+}$ and $3 \mathrm{SrO} \cdot 5 \mathrm{Al}_{2} \mathrm{O}_{3}: \mathrm{Mn}^{4+}$ under $380 \mathrm{~nm}$ is close to $18 \%, 27 \%$ respectively. ${ }^{14}$ The quantum efficiency of $\mathrm{La}_{2} \mathrm{LiTaO}_{6}: \mathrm{Mn}^{4+}, \mathrm{Mg}^{2+}$ is $21.4 \%{ }^{15}$ The internal and external quantum of $\mathrm{CaMg}_{2} \mathrm{Al}_{16} \mathrm{O}_{27}: \mathrm{Mn}^{4+}$ is $35.6 \%$ and $16.0 \%$ respectively. ${ }^{16}$ The highest external quantum reported for $\mathrm{Mn}^{4+}$ doped phosphors is about $80 \%$ for $\mathrm{Sr}_{2} \mathrm{MgAl}_{22} \mathrm{O}_{36}: \mathrm{Mn}^{4+}$, but the internal quantum efficiency which is more important for application is still needed identification. Moreover, the synthesis temperature for $\mathrm{Sr}_{2} \mathrm{MgAl}_{22} \mathrm{O}_{36}: \mathrm{Mn}^{4+}$ as high as $1500^{\circ} \mathrm{C}$ is not benefit for its application. ${ }^{17}$ Therefore, $\mathrm{Mn}^{4+}$ activated oxide phosphors with high internal quantum efficiency under low synthesis temperature focused recently. ${ }^{18}$

It is known that $\mathrm{Dy}^{3+}$ ions exhibit characteristic emissions of the blue and yellow regions corresponding to ${ }^{4} \mathrm{~F}_{9 / 2} \rightarrow{ }^{6} \mathrm{H}_{15 / 2}$ and ${ }^{4} \mathrm{~F}_{9 / 2} \rightarrow{ }^{6} \mathrm{H}_{13 / 2}$ transitions under the excitation of NUV light, and thus result the emission of near white-light. Due to the overlap of the emission spectrum of $\mathrm{Dy}^{3+}$ ions and the excitation spectrum of $\mathrm{Mn}^{4+}$ ions, the energy transfer process between $\mathrm{Dy}^{3+}$ ions and $\mathrm{Mn}^{4+}$ ions can be expected based on Dexter's energy transfer theory. ${ }^{19}$ Therefore, it is reasonable to believe $\mathrm{Dy}^{3+} /$ $\mathrm{Mn}^{4+}$ co-doped samples possess higher color rendering index (CRI) and lower color temperature than the single $\mathrm{Dy}^{3+}$-doped samples.

In our work, photoluminescence properties of $\mathrm{Mn}^{4+}$ doped and $\mathrm{Mn}^{4+} / \mathrm{Dy}^{3+}$ co-doped $\mathrm{Ca}_{14} \mathrm{Zn}_{6} \mathrm{Ga}_{10} \mathrm{O}_{35}$ (CZGO) are studies. 
The intense blue light emission of CZGO host was observed for first time. High quantum efficiency for $\mathrm{Mn}^{4+}$ doped CZGO was obtained. The internal and external quantum efficiencies of $\mathrm{Ca}_{14} \mathrm{Zn}_{6} \mathrm{Ga}_{9.85} \mathrm{O}_{35}: 0.15 \mathrm{Mn}^{4+}$ synthesized under $1210^{\circ} \mathrm{C}$ reached $64.4 \%$ and $56.2 \%$, the highest external quantum efficiency in $\mathrm{Mn}^{4+}$ activated oxide phosphors reported according to our knowledge. For $\mathrm{Dy}^{3+} / \mathrm{Mn}^{4+}$ co-doped CZGO, the CIE chromaticity coordinate $(0.345,0.275)$, color rendering index (CRI) 85 and color temperature $3525 \mathrm{~K}$ are obtained. Moreover, multiply energy transfer processes have been observed and discussed by Inokuti-Hirayama ( $\mathrm{I}-\mathrm{H})$ model and Dexter's theory. The results show that $\mathrm{Mn}^{4+}$ doped CZGO is a potential red phosphor for high performance white light LED devices.

\section{Experiment}

\subsection{Material synthesis}

$\mathrm{Ca}_{14-x} \mathrm{Zn}_{6} \mathrm{Ga}_{10-y} \mathrm{O}_{35}: x \mathrm{Dy}^{3+}, y \mathrm{Mn}^{4+}(x=0-0.18, y=0-0.25)$ were prepared by the solid-state reaction method. $\mathrm{CaCO}_{3}(99.9 \%$ purity), $\mathrm{ZnO}$ (99.9\% purity), $\mathrm{Ga}_{2} \mathrm{O}_{3}$ (99.9\% purity), $\mathrm{Dy}_{2} \mathrm{O}_{3}$ (99.99\% purity) and $\mathrm{MnO}_{2}$ (99.99\% purity) were used as the starting reactants. According to the stoichiometric composition, the reactants were weighed and mixed thoroughly in an agate mortar, then sintered in a tubular furnace at $1210^{\circ} \mathrm{C}$ for $6 \mathrm{~h}$ in air. After cooled down to the room temperature, the synthetic products were ground for subsequent analysis.

\subsection{Characterizations}

The phase compositions of the synthesized samples were studied using an Ultima IV X-ray diffractometer with $\mathrm{Cu} \mathrm{K} \alpha$ radiation $(\lambda=1.5406 \AA)$ operated at $36 \mathrm{kV}$ tube voltage and 20 $\mathrm{mA}$ tube current. The morphology of the samples were characterized using a S3400N scanning electron microscope (SEM). The PL spectra were obtained using a Hitachi F-7000 spectrophotometer at room temperature with a Xe lamp as source. Time-resolved photoluminescence decays were recorded by a FLS980 (Edinburgh) time-correlated single-photon counting (TCSPC) spectrofluorometer using an interchangeable Nano LED source for excitation. The temperature dependence of luminescence and photoluminescence quantum yields were measured by an Olsuka Electronics QE-2100 intensified multichannel spectrometer.

\section{Results and discussion}

\subsection{XRD and SEM analysis}

Fig. 1(a) shows the X-ray diffraction (XRD) patterns of $\mathrm{Ca}_{14-x^{-}}$ $\mathrm{Zn}_{6} \mathrm{Ga}_{10-y} \mathrm{O}_{35}: x \mathrm{Dy}^{3+}, y \mathrm{Mn}^{4+}(x, y=0,0 ; 0.1,0 ; 0,0.12 ; 0.1,0.12)$. All patterns of the samples are well in agreement with the standard XRD pattern of CZGO (\#245649). ${ }^{20}$ Fig. 1(b) shows the unit cells viewed from [100] for CZGO crystal which possesses cubic structure with space group $F 23$ (196) and lattice parameters $a=15.0794$ $\AA$ and $V=3428.88 \AA^{3}$. In the crystal lattice of CZGO, tetrahedral $\mathrm{GaO}_{4}$ and $\mathrm{ZnO}_{4}$ (partial disorder) share vertices to form a 3D network with two types of large empties. One type of these empties is filled with octahedral $(\mathrm{Ga}, \mathrm{Zn}) \mathrm{O}_{6}{ }^{-}$, while the other ones are half
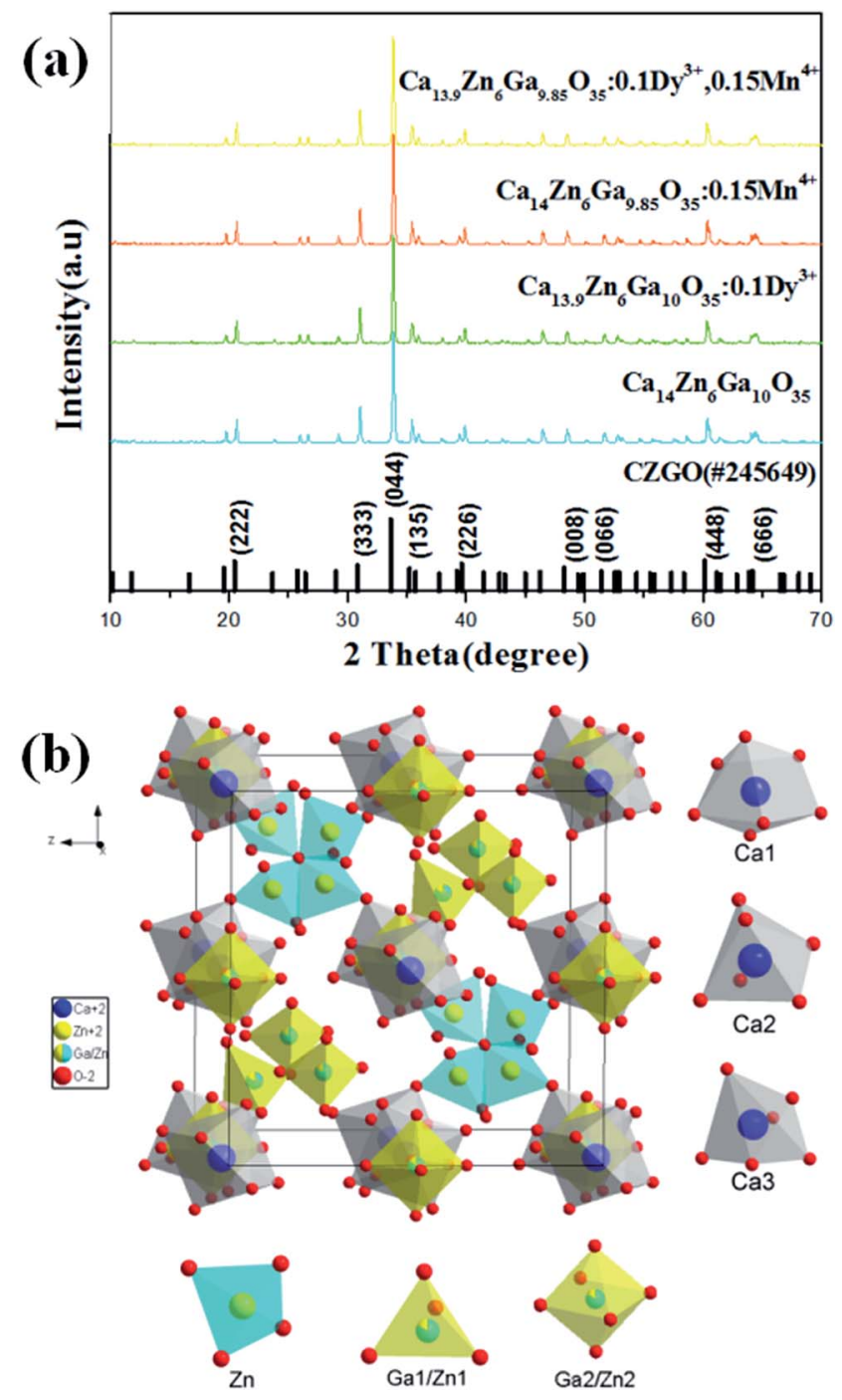

Fig. 1 (a) XRD patterns of $\mathrm{Ca}_{14-x} \mathrm{Zn}_{6} \mathrm{Ga}_{10-y} \mathrm{O}_{35}: \mathrm{XDy}^{3+}, y \mathrm{Mn}^{4+}(x, y=0$, $0 ; 0.1,0 ; 0,0.15 ; 0.1,0.15$ ). (b) A schematic of the CZGO crystal structure viewed in $x$-direction.

occupied by four corner-linked tetrahedral $\mathrm{ZnO}_{4}$ sharing common oxygen atom, according to Pauling's rules. ${ }^{21}$ On the basis of the effective ionic radii of cation with different coordination numbers (CN), ${ }^{22} \mathrm{Dy}^{3+}$ (6CN, $0.91 \AA$; 7CN, $0.97 \AA$ ) ions are expected to randomly occupy six- and seven-coordinated $\mathrm{Ca}^{2+}(6 \mathrm{CN}, 1.00 \AA$; 7CN, $1.06 \AA$ ) sites, and $\mathrm{Mn}^{4+}(6 \mathrm{CN}, 0.53 \AA$ ) ions are preferentially accommodated at the $\mathrm{Ga}^{3+}(6 \mathrm{CN}, 0.62 \AA)$ sites with an octahedral coordination in the crystal structure.

Fig. 2 displays the SEM image of $\mathrm{Ca}_{13.9} \mathrm{Zn}_{6} \mathrm{Ga}_{9.85} \mathrm{O}_{35}: 0.1 \mathrm{Dy}^{3+}$, $0.15 \mathrm{Mn}^{4+}$. The sample exhibits non-identical grains with the particle size approximately sub-micrometer to a few micrometers which tend to aggregate.

\subsection{High PL QEs of CZGO: $\mathrm{Mn}^{4+}$}

Fig. 3(a) shows the diffuse reflection spectra of $\mathrm{Ca}_{14} \mathrm{Zn}_{6} \mathrm{Ga}_{10-y^{-}}$ $\mathrm{O}_{35}: \mathrm{Mn}^{4+}(y=0.00,0.03,0.12$, and 0.25$)$. There are three dips of reflectivity between 280 and $550 \mathrm{~nm}$. Two dips locating at 332 and $465 \mathrm{~nm}$ are assigned to strong spin-allowed transitions in 


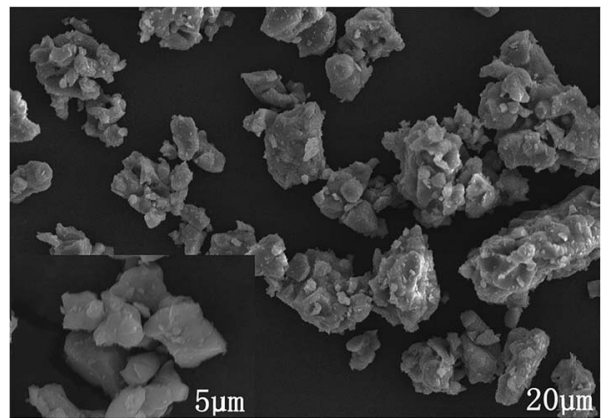

Fig. 2 SEM image of $\mathrm{Ca}_{13.9} \mathrm{Zn}_{6} \mathrm{Ga}_{9.85} \mathrm{O}_{35}: 0.1 \mathrm{Dy}^{3+}, 0.15 \mathrm{Mn}^{4+}$ sample.
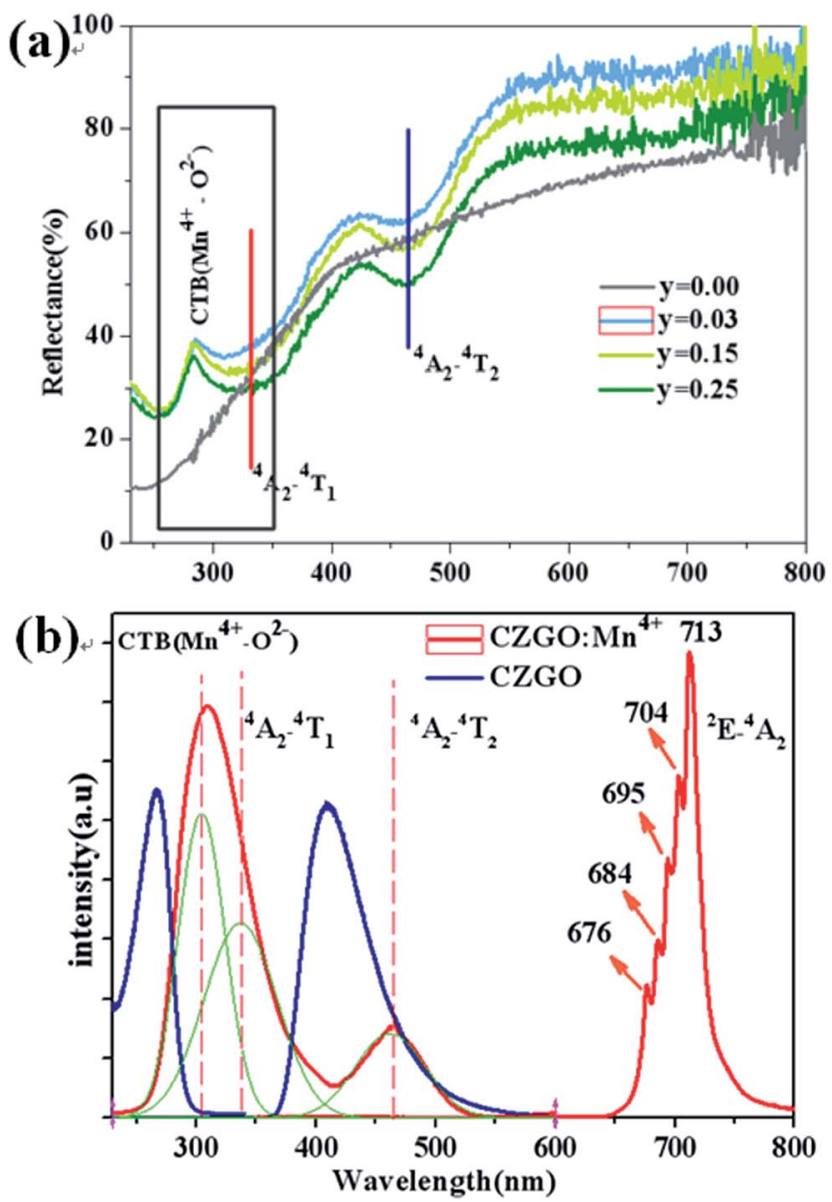

Fig. 3 (a) Representative diffuse reflection spectra of $\mathrm{Ca}_{14} \mathrm{Zn}_{6}$ $\mathrm{Ga}_{10-y} \mathrm{O}_{35}: \mathrm{yMn}^{4+}(y=0.00,0.03,0.12,0.25)$. (b) PLE and PL of CZGO $\left(\lambda_{\mathrm{em}}=410 \mathrm{~nm}, \lambda_{\mathrm{ex}}=266 \mathrm{~nm}\right)$ and $\mathrm{Ca}_{14} \mathrm{Zn}_{6} \mathrm{Ga}_{9.99} \mathrm{O}_{35}: 0.01 \mathrm{Mn}^{4+}\left(\lambda_{\mathrm{em}}=\right.$ $\left.713 \mathrm{~nm}, \lambda_{\mathrm{ex}}=310 \mathrm{~nm}\right)$.

$\mathrm{Mn}^{4+}$ ions corresponding to ${ }^{4} \mathrm{~A}_{2} \rightarrow{ }^{4} \mathrm{~T}_{2}$ and ${ }^{4} \mathrm{~A}_{2} \rightarrow{ }^{4} \mathrm{~T}_{1}$, respectively. The broad dip in the range of $250-350 \mathrm{~nm}$ is aroused by both $\mathrm{Mn}^{4+}-\mathrm{O}^{2-}$ charge transfer transition and ${ }^{4} \mathrm{~A}_{2} \rightarrow{ }^{4} \mathrm{~T}_{1}$ transition of $\mathrm{Mn}^{4+}$ ions, which can be judged from the excitation spectra as below.

PLE and PL of CZGO $\left(\lambda_{\mathrm{em}}=410 \mathrm{~nm}, \lambda_{\mathrm{ex}}=266 \mathrm{~nm}\right)$ and $\mathrm{Ca}_{14} \mathrm{Zn}_{6} \mathrm{Ga}_{9.99} \mathrm{O}_{35}: 0.01 \mathrm{Mn}^{4+}\left(\lambda_{\mathrm{em}}=713 \mathrm{~nm}, \lambda_{\mathrm{ex}}=310 \mathrm{~nm}\right)$ are shown in Fig. 3(b). For CZGO, an absorption band from about $200 \mathrm{~nm}$ to $300 \mathrm{~nm}$ centered at $266 \mathrm{~nm}$ (monitored emission wavelength $\lambda_{\mathrm{em}}=410 \mathrm{~nm}$ ) and a broad-band PL blue emission centered at $410 \mathrm{~nm}$ extend from $360 \mathrm{~nm}$ to $500 \mathrm{~nm}$ (excitation wavelength $\lambda_{\mathrm{ex}}=266 \mathrm{~nm}$ ) of CZGO are observed. The broadband blue emission has not been reported in CZGO before, ${ }^{19,20}$ but similar blue emission was observed in $\mathrm{ZnGa}_{2} \mathrm{O}_{4}$ crystals owning to the distorted octahedral $\mathrm{Ga}-\mathrm{O}$ groups serving as the self-activated luminescent centers. ${ }^{23-27}$ It is reasonable to ascribe the broad-band blue emission to the recombination of a donor-acceptor pair (DAP) through a tunneling process in CZGO host. For $\mathrm{Ca}_{14} \mathrm{Zn}_{6} \mathrm{Ga}_{9.97} \mathrm{O}_{35}: 0.03 \mathrm{Mn}^{4+}$, the excitation spectrum can be fitted by three Gaussian curves, leading to three distinguished bands peaking at 303 (band I, $33003 \mathrm{~cm}^{-1}$ ), 332 (band II, $30120 \mathrm{~cm}^{-1}$ ) and 465 (band III, $21505 \mathrm{~cm}^{-1}$ ) which are in good agreement with those in the diffuse reflection spectra. The excitation bands located at 332 and $465 \mathrm{~nm}$ are assigned to the spin-allowed $\left({ }^{4} \mathrm{~A}_{2} \rightarrow{ }^{4} \mathrm{~T}_{2}\right)$ and $\left({ }^{4} \mathrm{~A}_{2} \rightarrow{ }^{4} \mathrm{~T}_{1}\right)$ transitions of $\mathrm{Mn}^{4+}$, respectively. The broad band, which is composed by bands I and II, is due to the overlap between the transitions of $\mathrm{Mn}^{4+}-\mathrm{O}^{2-}$ and the spin-allowed transitions of $\mathrm{Mn}^{4+}\left({ }^{4} \mathrm{~A}_{2} \rightarrow{ }^{4} \mathrm{~T}_{1}\right)$. Under excitation at $310 \mathrm{~nm}$, the intense red emission is composed of some distinguishable sharp $\mathrm{R}$ lines and Stokes/anti-Stokes side-peaks, located at 676, 684, 695, 704 and $713 \mathrm{~nm}$, due to different vibrational modes for the $3 \mathrm{~d}^{3}$ electrons when $\mathrm{Mn}^{4+}$ is of the octahedral complex. ${ }^{28}$ Although there is an overlap between the PLE spectrum of CZGO and $\mathrm{Mn}^{4+}$ ion, our measurement for the average lifetimes of the PL spectrum of CZGO with different $\mathrm{Mn}^{4+}$ concentration suggesting there is no energy transfer between CZGO and $\mathrm{Mn}^{4+}$.

The energy splitting of $\mathrm{Mn}^{4+}$ ion with octahedral coordination on the crystal field strength can be well illustrated by Tanabe-Sugano energy diagram (Fig. 4). ${ }^{29}$ The value of the local crystal-field parameter $D_{\mathrm{q}}$ can be obtained from the peak energy $\left(21505 \mathrm{~cm}^{-1}\right.$ ) of the ${ }^{4} \mathrm{~A}_{2} \rightarrow{ }^{4} \mathrm{~T}_{2}$ transition ${ }^{30}$

$$
D_{\mathrm{q}}=E\left({ }^{4} \mathrm{~A}_{2 \mathrm{~g}} \rightarrow{ }^{4} \mathrm{~T}_{2 \mathrm{~g}}\right) / 10
$$

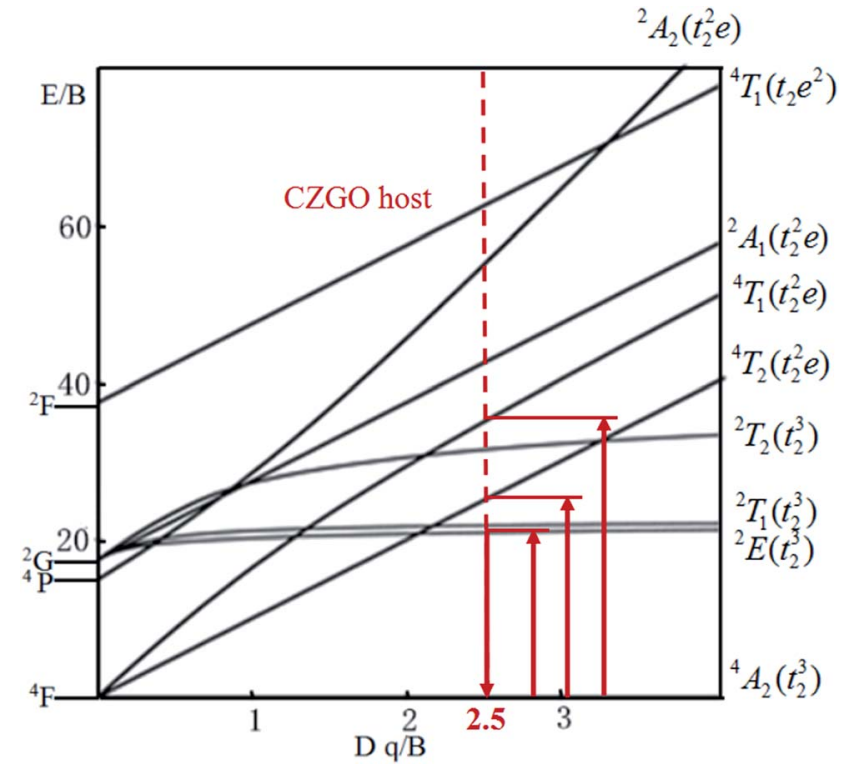

Fig. 4 Tanabe-Sugano diagram for $\mathrm{Mn}^{4+}$ in CZGO. 
Moreover, based on the obtained energy difference (8615 $\mathrm{cm}^{-1}$ ) between the ${ }^{4} \mathrm{~A}_{2} \rightarrow{ }^{4} \mathrm{~T}_{2}$ and ${ }^{4} \mathrm{~A}_{2} \rightarrow{ }^{4} \mathrm{~T}_{1}$ transitions, Racah parameter $B$ can be evaluated from the expression ${ }^{31}$

$$
\frac{D_{\mathrm{q}}}{B}=\frac{15(x-8)}{\left(x^{2}-10 x\right)}
$$

here the parameter $x$ is defined as

$$
x=\frac{E\left({ }^{4} \mathrm{~A}_{1} \rightarrow{ }^{4} \mathrm{~T}_{1}\right)-E\left({ }^{4} \mathrm{~A}_{1} \rightarrow{ }^{4} \mathrm{~T}_{2}\right)}{D_{\mathrm{q}}}
$$

According to the peak energy $\left(14025 \mathrm{~cm}^{-1}\right)$ corresponding to ${ }^{2} \mathrm{E} \rightarrow{ }^{4} \mathrm{~A}_{2}$ transition of $\mathrm{Mn}^{4+}$ derived from emission spectrum above, Racah parameter $C$ can be calculated by the following eqn $^{32}$

$$
E\left({ }^{2} \mathrm{E} \rightarrow{ }^{2} \mathrm{~A}_{2}\right) / B=3.05 C / B+7.9-1.8 B / D_{\mathrm{q}}
$$

The values of $D_{\mathrm{q}}, B$ and $C$ in the CZGO: $\mathrm{Dy}^{3+}, \mathrm{Mn}^{4+}$ are then determined to be 2150,860 and $2572 \mathrm{~cm}^{-1}$, respectively. The values of $B$ is higher than those reported in oxides while the values of $C$ is smaller than those reported in oxides, and the values of $D_{\mathrm{q}}$ is similar to those reported in oxides. ${ }^{33}$ In fact, the emission peak energy of ${ }^{2} \mathrm{E} \rightarrow{ }^{4} \mathrm{~A}_{2}$ transition is singularly dependent on the covalence of the " $\mathrm{Mn}^{4+}$-ligand" bonding (nephelauxetic effect). The nephelauxetic ratio $\beta$ can be determined by following equation: ${ }^{34}$

$$
\beta=\sqrt{\left(B / B_{0}\right)^{2}+\left(C / C_{0}\right)^{2}}
$$

here $B_{0}$ and $C_{0}$ represent Racah parameters for free ions. For $\mathrm{Mn}^{4+}$ ions, $B_{0}$ and $C_{0}$ are equal to $1160 \mathrm{~cm}^{-1}$ and $4303 \mathrm{~cm}^{-1}$, respectively. ${ }^{35}$ So $\beta$ for $\mathrm{Mn}^{4+}$ in CZGO is calculated to be 0.952 . This value is similar to those reported in oxides, but higher than those in fluorides, due to the more ionic $\mathrm{Mn}^{4+}-\mathrm{F}^{-}$bonding than $\mathrm{Mn}^{4+}-\mathrm{O}^{2-}$ bonding. ${ }^{36}$

Fig. 5 shows PL spectra $\left(\lambda_{\text {ex }}=310 \mathrm{~nm}\right)$ of $\mathrm{Ca}_{14} \mathrm{Zn}_{6} \mathrm{Ga}_{10-y^{-}}$ $\mathrm{O}_{35}: y \mathrm{Mn}^{4+}$ phosphors as a function of $y$ at room temperature. The PL intensity of $\mathrm{Mn}^{4+}$ ions increases with increased $\mathrm{Mn}^{4+}$

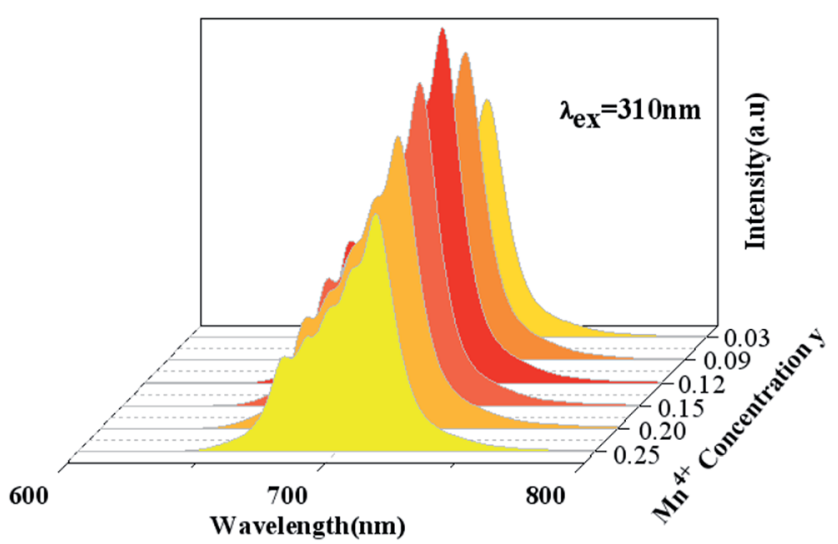

Fig. 5 Photoluminescence emission spectra of $\mathrm{Ca}_{14} \mathrm{Zn}_{6} \mathrm{Ga}_{10-y} \mathrm{O}_{35}$ :$y \mathrm{Mn}^{4+}(y=0.03,0.09,0.12,0.15,0.20,0.25)$ under $\lambda_{\mathrm{ex}}=310 \mathrm{~nm}$. concentration, and concentration quenching occurs beyond $y=$ 0.15. Photoluminescence internal and external quantum efficiency of $\mathrm{Ca}_{14} \mathrm{Zn}_{6} \mathrm{Ga}_{10-y} \mathrm{O}_{35}: \mathrm{Mn}^{4+}$ phosphors is measured in Table 1. The photoluminescence internal an external quantum efficiencies (QEs) reach $64.4 \%$ and $56.2 \%$ respectively when $y=$ 0.15 . Although the internal quantum efficiency of our sample is lower than the phosphor $\mathrm{Sr}_{2} \mathrm{MgAl}_{22} \mathrm{O}_{36}: \mathrm{Mn}^{4+}$ reported by Renping $\mathrm{Cao}^{\mathbf{1 7}}$ the external quantum efficiency of our sample has been the highest one according to our knowledge.

The temperature-dependent emission spectra is shown in Fig. 6, and two features can be observed: (1) emission intensity decreases with temperature increasing (2) all emission peaks shift to longer wavelength (red shift) region with increasing temperature.

The Arrhenius equation can be used to evaluate activation energy $\Delta E$ for thermal quenching: ${ }^{37}$

$$
I_{T}=I_{0} /[1+c \exp (-\Delta E / k T)]
$$

here $I_{0}$ is the initial emission intensity, $I_{T}$ is the intensity at temperature $T, c$ is a constant, $k$ is the Boltzmann constant, and $\Delta E$ is the activation energy for thermal quenching. Based on the PL spectra in Fig. 6, the $\Delta E$ of CZGO: $\mathrm{Mn}^{4+}$ is obtained as $0.156 \mathrm{eV}$ by fitting the curve of $\ln \left[\left(I_{0} / I_{T}\right)-1\right]$ versus $1 / k T$, as shown in the inset of Fig. 6.

The peak position, the internal and external QEs are shown in Table 2. The peak position shifts from 713.4 to $716.6 \mathrm{~nm}$ as temperature from $298 \mathrm{~K}$ to $573 \mathrm{~K}$. The red-shift behavior can be

Table 1 Photoluminescence internal and external QEs at different $y$ in $\mathrm{Ca}_{14} \mathrm{Zn}_{6} \mathrm{Ga}_{10-y} \mathrm{O}_{35}: \mathrm{yMn}^{4+}$ phosphors excited at $310 \mathrm{~nm}$

\begin{tabular}{ccccccc}
\hline$y$ & 0.03 & 0.09 & 0.12 & 0.15 & 0.20 & 0.25 \\
Internal QE (\%) & 41.3 & 49.5 & 59.4 & 64.4 & 54.6 & 44.6 \\
External QE (\%) & 36.2 & 43.7 & 52.4 & 56.2 & 48.2 & 38.3
\end{tabular}

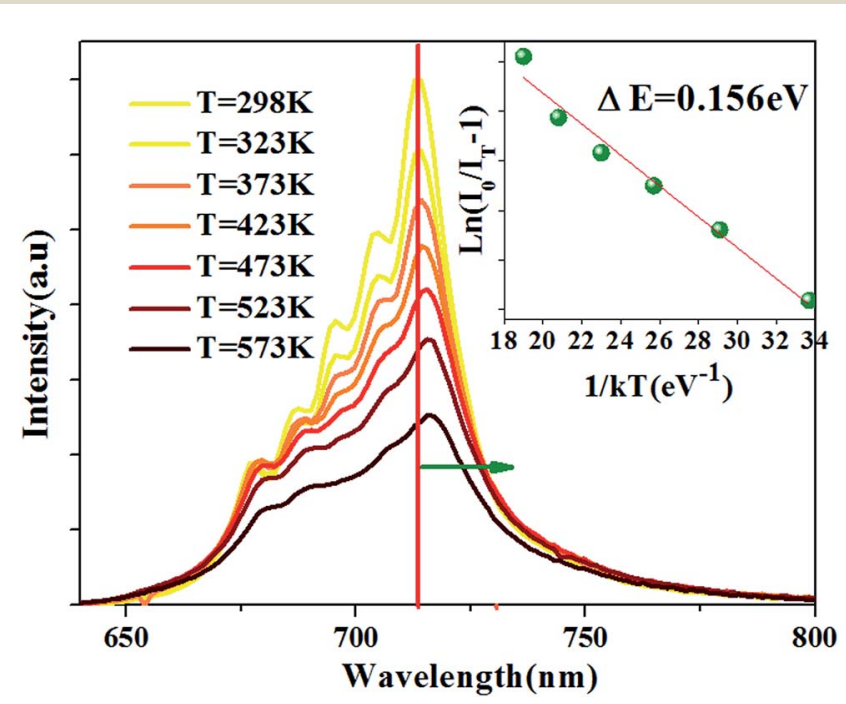

Fig. $6 \mathrm{PL}$ spectra at different temperature for the $\mathrm{Ca}_{14} \mathrm{Zn}_{6} \mathrm{Ga}_{9.85^{-}}$ $\mathrm{O}_{35}: 0.15 \mathrm{Mn}^{4+}$ excited at $310 \mathrm{~nm}$. The inset: the activation energy $0.156 \mathrm{eV}$ for $\mathrm{Ca}_{14} \mathrm{Zn}_{6} \mathrm{Ga}_{9.85} \mathrm{O}_{35}: 0.15 \mathrm{Mn}^{4+}$. 
Table 2 The peak position, internal and external QEs of $\mathrm{Ca}_{14} \mathrm{Zn}_{6}$ $\mathrm{Ga}_{9.85} \mathrm{O}_{35}: 0.15 \mathrm{Mn}^{4+}$ at different temperature

\begin{tabular}{lccccccc}
\hline Temperature (K) & 298 & 323 & 373 & 423 & 473 & 523 & 573 \\
Peak (nm) & 713.4 & 714.0 & 714.3 & 715.0 & 715.6 & 715.9 & 716.6 \\
Internal QE (\%) & 64.4 & 63.7 & 61.4 & 59.4 & 56.4 & 53.0 & 45.9 \\
External QE (\%) & 56.2 & 55.4 & 53.4 & 51.6 & 49.0 & 46.1 & 39.9
\end{tabular}

explained by the Varshini equation for temperature dependence ${ }^{38,39}$

$$
E(T)=E_{0}-\frac{a T^{2}}{T+b}
$$

where $E(T)$ is the energy difference between excited states and ground states at a temperature $T, E_{0}$ is the energy difference at $0 \mathrm{~K}$, and $a$ and $b$ are fitting parameters. The bond lengths between the luminescent center and its ligand ions increase with increased temperature, which results in the decreased crystal field. Then, it will cause the split of degenerate excited state or ground state, resulting in the decrease of the transition energy. Therefore, the emission peak is red-shifted with the increase of temperature. ${ }^{40}$ The red-shift behavior can also be explained by Tanabe-Sugano energy diagram (Fig. 4), decreased crystal field correspond to less value of $D_{\mathrm{q}} / B$, resulting in the smaller transition energy between excited state ${ }^{2} \mathrm{E}$ and ground state ${ }^{4} \mathrm{~A}_{2}$.

Both internal QE and external QE decreases with increased temperature. The internal and external QEs decrease $28.7 \%$ and $29.0 \%$ of the values at $298 \mathrm{~K}$, respectively. Almost the same decreasing rate indicates that the change of QEs with temperature is not brought by the change of the absorption of the incident light on the phosphors.

\subsection{White light of CZGO:Dy ${ }^{3+}$}

Fig. 7 displays the PL and PLE spectra of $\mathrm{Ca}_{13.9} \mathrm{Zn}_{6} \mathrm{Ga}_{10^{-}}$ $\mathrm{O}_{35}: 0.1 \mathrm{Dy}^{3+}\left(\lambda_{\mathrm{em}}=410 \mathrm{~nm}\right.$ and $486 \mathrm{~nm}, \lambda_{\mathrm{ex}}=266 \mathrm{~nm}$ and 352 $\mathrm{nm})$. The broad emission blue band centered at $410 \mathrm{~nm}$ is obviously from СТВ of host. The absorption peak centered at $352 \mathrm{~nm}$ and the sharp emission bands centered at $486 \mathrm{~nm}$ and $578 \mathrm{~nm}$ come from the transition ${ }^{6} \mathrm{H}_{15 / 2} \rightarrow{ }^{6} \mathrm{P}_{7 / 2},{ }^{4} \mathrm{~F}_{9 / 2} \rightarrow{ }^{6} \mathrm{H}_{13 / 2}$ and ${ }^{4} \mathrm{~F}_{9 / 2} \rightarrow{ }^{6} \mathrm{H}_{15 / 2}$ for Dy ${ }^{3+}$ ion respectively. It can be seen that the emission spectrum under the excitation $266 \mathrm{~nm}$ have the similar profile with that excited at $352 \mathrm{~nm}$ except for the appearance of the wide band centered at $410 \mathrm{~nm}$. In addition to, the intensity of emission excited at $266 \mathrm{~nm}$ is much times higher than the emission excited at $352 \mathrm{~nm}$, which indicating the high photon energy that host absorbed can be transferred efficiently to $\mathrm{Dy}^{3+}$ ion.

The dependence of the emission host intensities of $\mathrm{Ca}_{14-x^{-}}$ $\mathrm{Zn}_{6} \mathrm{Ga}_{10} \mathrm{O}_{35}: x \mathrm{Dy}^{3+}$ phosphors on $\mathrm{Dy}^{3+}$ concentration $x$ is shown in Fig. 8. The change of the intensity for ${ }^{4} \mathrm{~F}_{9 / 2} \rightarrow{ }^{6} \mathrm{H}_{13 / 2},{ }^{6} \mathrm{H}_{15 / 2}$ transition shows the feature of concentration quenching with the maximum intensity as $x=0.1$. However, the blue intensity for host decreases monotonically with $x$ increase, indicating further the existence of the energy transfer from the host to $\mathrm{Dy}^{3+}$ ions.

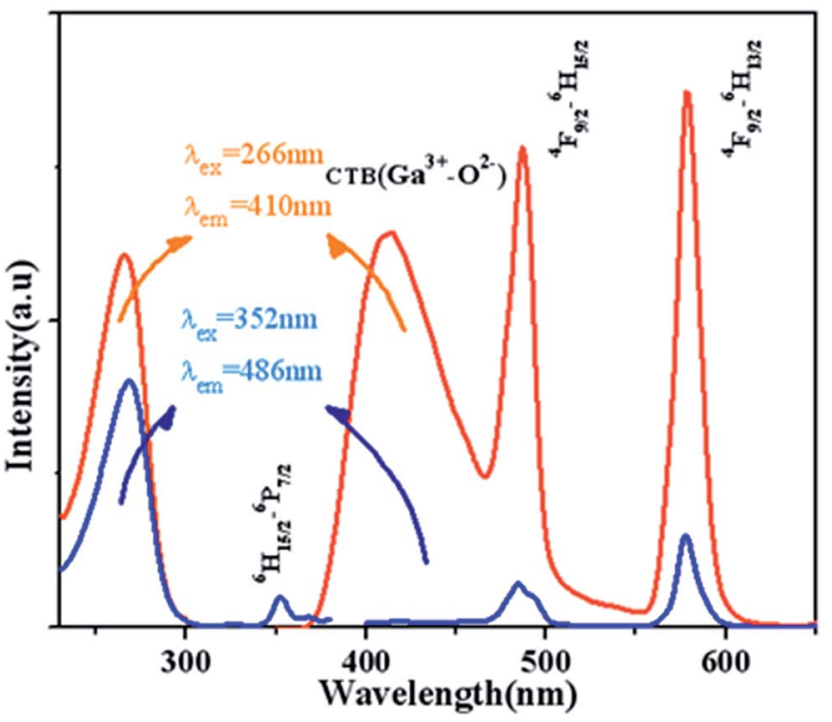

Fig. $7 \mathrm{PL}$ and PLE spectra of $\mathrm{Ca}_{13.9} \mathrm{Zn}_{6} \mathrm{Ga}_{10} \mathrm{O}_{35}: 0.1 \mathrm{Dy}^{3+}\left(\lambda_{\mathrm{em}}=410 \mathrm{~nm}\right.$ and $486 \mathrm{~nm}, \lambda_{\mathrm{ex}}=266 \mathrm{~nm}$ and $352 \mathrm{~nm}$ ).

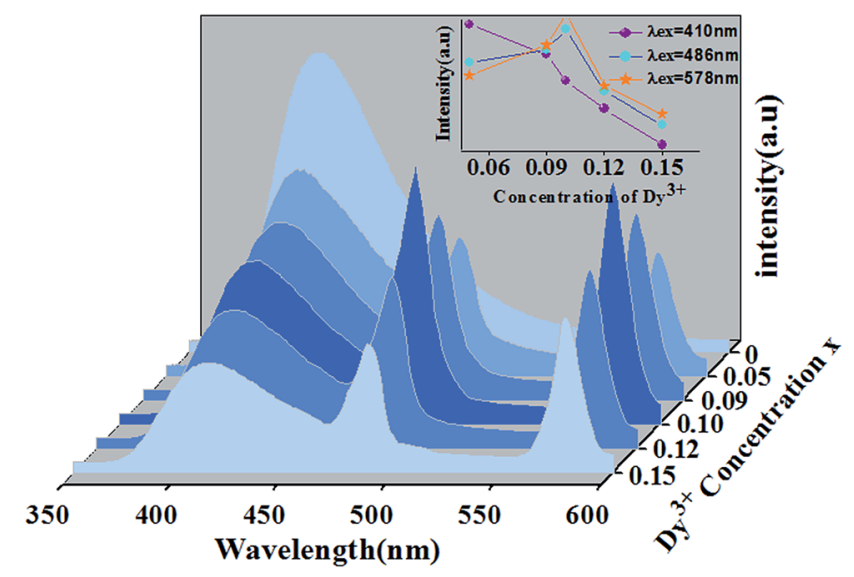

Fig. 8 Emission spectra of $\mathrm{Ca}_{14-x} \mathrm{Zn}_{6} \mathrm{Ga}_{10} \mathrm{O}_{35}: x \mathrm{Dy}{ }^{3+}$ under the excitation of $266 \mathrm{~nm}$. The inset shows the dependence of three emission peakshost on $\mathrm{Dy}^{3+}$ concentration.

An energy band diagram is proposed in Fig. 9. The broadband blue emission of host is suggested to be ascribed to the recombination of a donor-acceptor pair (DAP) through a tunneling process, that is, from the transition between electrons trapped by the donor band (DB) (being formed by oxygen vacancies) and holes captured by the acceptor band (AB) (being formed by gallium vacancy) $\left(\mathrm{V}_{\mathrm{Ga}}\right)$, or pair of gallium vacancy and oxygen vacancy $\left(\mathrm{V}_{\mathrm{O}}, \mathrm{V}_{\mathrm{Ga}}\right)$. It is worth noting that the absorption energy $(4.7 \mathrm{eV}, 266 \mathrm{~nm})$ of host is located at approximately twice the energy of the $\mathrm{Dy}^{3+}:{ }^{4} \mathrm{~F}_{9 / 2} \rightarrow{ }^{6} \mathrm{H}_{13 / 2}(2.1 \mathrm{eV}, 578 \mathrm{~nm})$ or ${ }^{4} \mathrm{~F}_{9 / 2} \rightarrow$ ${ }^{6} \mathrm{H}_{15 / 2}(2.5 \mathrm{eV}, 486 \mathrm{~nm})$ transition. Moreover, absorption bands of the host and $\mathrm{Dy}^{3+}$ are almost overlapped in Fig. 7, which means the energy transfer process from the host to $\mathrm{Dy}^{3+}$ is dominated by the cooperative energy transfer. ${ }^{41,42}$ The cooperative energy transfer between the CZGO host and $\mathrm{Dy}^{3+}$ ions can be understood as following: in first step, the electrons in the 


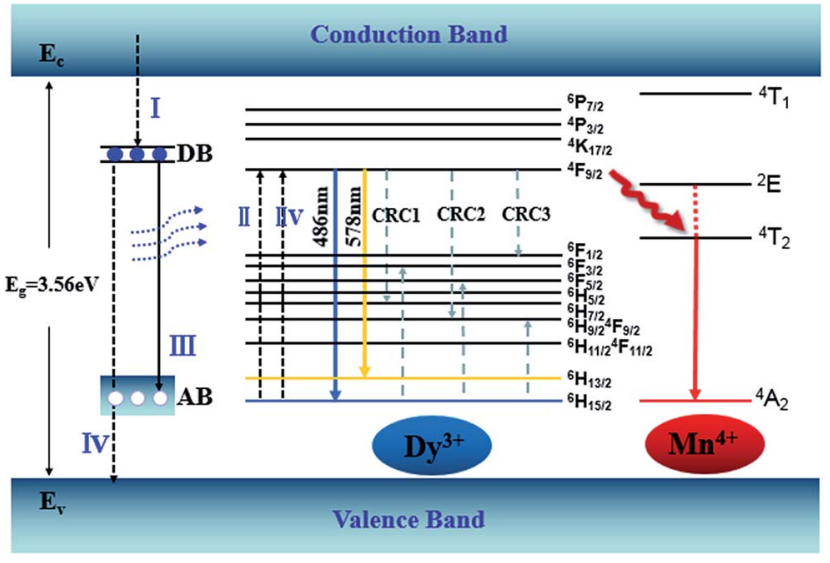

Fig. 9 Energy level diagram showing energy transfer and the CR processes of CZGO:Dy ${ }^{3+}, \mathrm{Mn}^{4+}$.

conduction band de-excite to DB (process I in Fig. 9), accompanying the excitation of $\mathrm{Dy}^{3+}$ from ${ }^{6} \mathrm{H}_{15 / 2}$ to ${ }^{4} \mathrm{~F}_{9 / 2}$ (process II in Fig. 9) followed by the emission of $\mathrm{Dy}^{3+}\left({ }^{4} \mathrm{~F}_{9 / 2} \rightarrow{ }^{6} \mathrm{H}_{13 / 2}\right.$ and ${ }^{4} \mathrm{~F}_{9 / 2}$ $\rightarrow{ }^{6} \mathrm{H}_{15 / 2}$ ); In second step, the electrons in DB can either deexcite to $A B$ (process III in Fig. 9) which results the emission of the host, or to valance band (process IV in Fig. 9) which results the excitation of Dy ${ }^{3+}$ from ${ }^{6} \mathrm{H}_{15 / 2}$ to ${ }^{4} \mathrm{~F}_{9 / 2}$ (process IIV in Fig. 9) followed by the emission of $\mathrm{Dy}^{3+}$. The concentration quenching of $\mathrm{Dy}^{3+}$ emission intensity can be ascribed to the cross relaxation between neighboring $\mathrm{Dy}^{3+}$ ions. Cross relaxation (CR) occurs when the energy from excited states promotes the ground state to the metastable levels. For $\mathrm{Dy}^{3+}$ ions, the $\mathrm{CR}$ mechanisms $\left[{ }^{4} \mathrm{~F}_{9 / 2},{ }^{6} \mathrm{H}_{15 / 2}\right] \rightarrow\left[{ }^{6} \mathrm{H}_{7 / 2} /{ }^{4} \mathrm{~F}_{9 / 2},{ }^{6} \mathrm{~F}_{3 / 2}\right],\left[{ }^{4} \mathrm{~F}_{9 / 2},{ }^{6} \mathrm{H}_{15 / 2}\right]$ $\rightarrow\left[{ }^{6} \mathrm{H}_{9 / 2} /{ }^{6} \mathrm{~F}_{11 / 2},{ }^{6} \mathrm{~F}_{5 / 2}\right]$ and $\left[{ }^{4} \mathrm{~F}_{9 / 2},{ }^{6} \mathrm{H}_{15 / 2}\right] \rightarrow\left[{ }^{6} \mathrm{~F}_{1 / 2},{ }^{6} \mathrm{H}_{9 / 2} /{ }^{6} \mathrm{~F}_{11 / 2}\right]$ denoted by CRC1, CRC2, and CRC3, respectively, are possible responsible to the concentration quenching based on the energy match rule, as illustrated in Fig. 9.

The fluorescence decay curves of $\mathrm{Ca}_{14-x} \mathrm{Zn}_{6} \mathrm{Ga}_{10} \mathrm{O}_{35}: x \mathrm{Dy}^{3+}(x$ $=0.00,0.05,0.09,0.10,0.12,0.15)$ monitored at $410 \mathrm{~nm}$ with the excitation of $266 \mathrm{~nm}$ are shown in Fig. 11. The curve can be nearly fitted by one exponential function, and the average lifetime $\tau$ is given by ${ }^{43}$

$$
\tau=\int_{0}^{\infty} t I(t) \mathrm{d} t / \int_{0}^{\infty} I(t) \mathrm{d} t
$$

where $I(t)$ is the luminescent intensity at time $t$. The obtained $\tau$ is given in the inset of Fig. 10. The lifetime decreased from 32.8 $\mu$ s to $22.6 \mu$ s when the concentration of $\mathrm{Dy}^{3+}$ increased from 0.05 to 0.15 . The decrease of lifetime with increase of $\mathrm{Dy}^{3+}$ concentration confirms the existence of the energy transfer between host and $\mathrm{Dy}^{3+}$ ions.

In order to figure out the interaction type of energy transfer between host and $\mathrm{Dy}^{3+}$ ions, the donor centers of oxygen vacancies marked as "A", are considered. If " $\mathrm{A}$ " and $\mathrm{Dy}^{3+}$ ions are randomly distributed in the host and the migration processes among $\mathrm{Dy}^{3+}$ ions are negligible, then the temporal evolution of the $\mathrm{Dy}^{3+}$ luminescence intensity $I(t)$, following pulsed excitation at $266 \mathrm{~nm}$, can be given by the Inokuti-Hirayama (I-H) model ${ }^{44}$

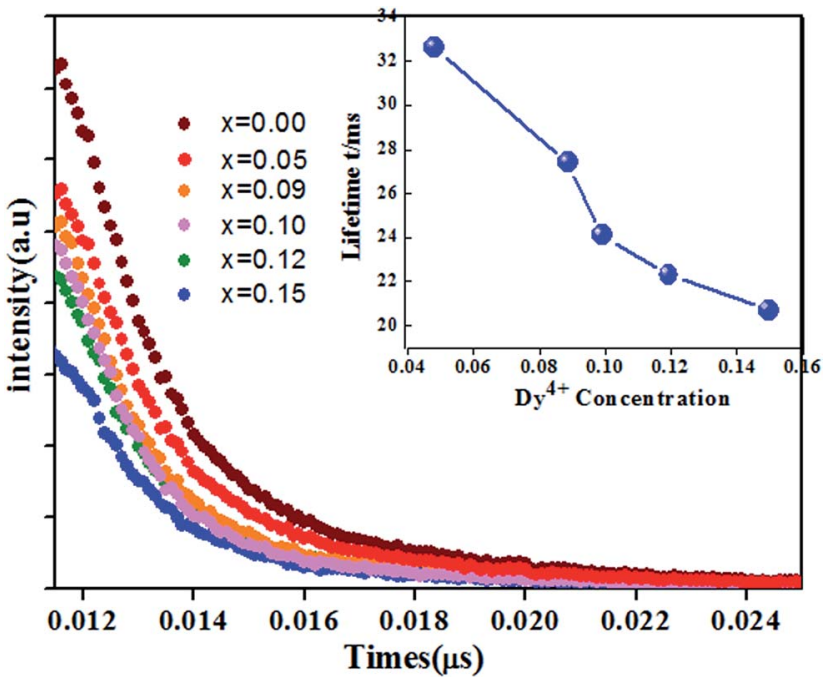

Fig. 10 Luminescence decay curves of $\mathrm{Ca}_{14-x} \mathrm{Zn}_{6} \mathrm{Ga}_{9.88} \mathrm{O}_{35}: \mathrm{xDy}^{3+}(x$ $=0.00,0.05,0.09,0.10,0.12,0.15$ ) (monitored at $410 \mathrm{~nm}$ excited at $266 \mathrm{~nm}$ ). The inset: dependence of the lifetime $\tau$ and energy transfer efficiency $\eta$ on $\mathrm{Dy}^{3+}$ doping concentration.

$$
I(t)=I(0) \exp \left(-\frac{t}{\tau_{0}}-\gamma t^{\frac{3}{S}}\right)
$$

where $I(0)$ is luminescence intensity when $t=0, \tau_{0}$ is the lifetime of the host in the absence of $\mathrm{Dy}^{3+}$ ions, $S$ is the multipolar interaction parameter, and the energy transfer parameter $\gamma$ is defined by

$$
\gamma=\frac{4 \pi}{3} C_{\mathrm{A}} \Gamma\left(1-\frac{3}{S}\right)\left(C_{\mathrm{DA}}{ }^{(S)}\right)^{\frac{3}{S}}
$$

in which $C_{\mathrm{A}}$ is $\mathrm{Dy}^{3+}$ concentration, $\Gamma(x)$ is the gamma function, and $C_{\mathrm{DA}}{ }^{(\mathrm{S})}$ is the "A" $\rightarrow \mathrm{Dy}^{3+}$ energy transfer parameter. The decay curves for the samples doped with $5 \mathrm{~mol} \%$ and $10 \mathrm{~mol} \%$ of $\mathrm{Dy}^{3+}$ ions are presented in Fig. 11. The best fitting using $\mathrm{I}-\mathrm{H}$ model is $S=6$, indicating the energy transfer between the host and $\mathrm{Dy}^{3+}$ ions is dominantly governed by dipole-dipole interaction.

Considering no overlap between PLE and PL spectra of $\mathrm{Dy}^{3+}$, the concentration quenching of $\mathrm{Dy}^{3+}$ emission cannot be related to the radiation re-absorption. It might be attributed to multipole-multipole interaction or exchange interaction. In order to figure out this point, the average distance $\left(R_{\mathrm{c}}\right)$ between the nearest $\mathrm{Dy}^{3+}$ ions can roughly be calculated using the following eqn..$^{45}$

$$
R_{\mathrm{C}} \approx 2\left[\frac{3 V}{4 \pi X_{\mathrm{c}} N}\right]^{\frac{1}{3}}
$$

where $V$ is the volume of the unit cell; $N$ is the number of host cations which can be replaced by $\mathrm{Dy}^{3+}$ ions in the unit cell; $X_{\mathrm{c}}$ is the critical concentration of $\mathrm{Dy}^{3+}$ ion. For this case, $V=3428.88$ $\AA^{3}, N=4, X_{\mathrm{c}}=0.10, R_{\mathrm{c}}$ is obtained to be $25 \AA$. Blasse ${ }^{46}$ has pointed out that multipolar interaction predominates if $R_{\mathrm{c}}$ is larger than $5 \AA$. Therefore, the multipolar interaction accounts for the concentration quenching in CZGO:Dy ${ }^{3+}$ phosphors. 


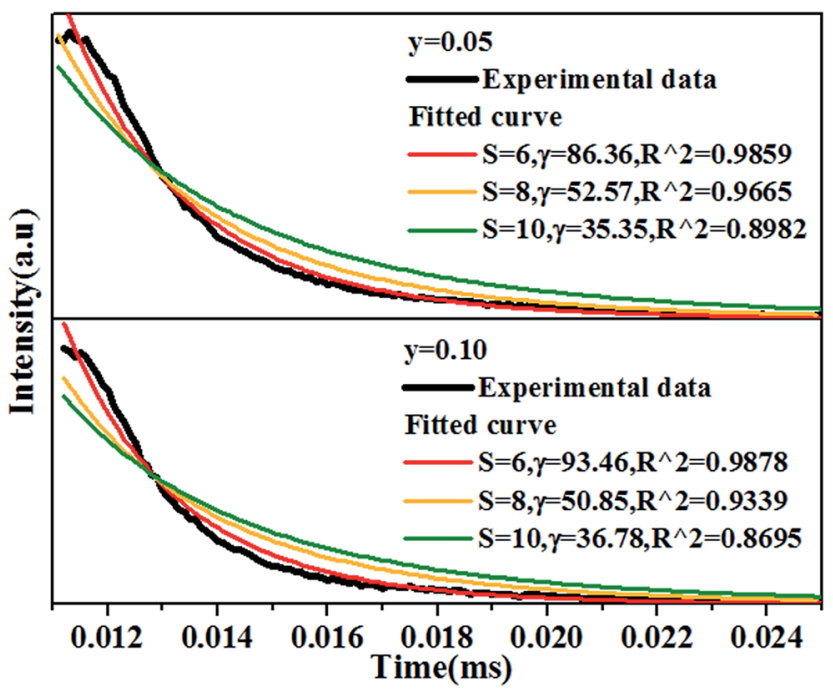

Fig. 11 Decay curves of $\mathrm{Ca}_{14-x} \mathrm{Zn}_{6} \mathrm{Ga}_{10} \mathrm{O}_{35}: x \mathrm{Dy}^{3+},(x=0.05,0.10)$ measured by $266 \mathrm{~nm}$ excitation and monitored at $410 \mathrm{~nm}$, together with the fitted curves using $\mathrm{I}-\mathrm{H}$ model, showing the best fitting when $S$ $=6$. All the experimental data of samples.

Based on the model proposed by Dexter, ${ }^{47}$ the interaction type between $\mathrm{Dy}^{3+}$ ions can be identified by

$$
I / x=\left[1+\beta(x)^{\theta / 3}\right]^{-1}
$$

where $I$ is the emission intensity of $\mathrm{Dy}^{3+}$ ion under the excitation of $352 \mathrm{~nm}$; $x$ is $\mathrm{Dy}^{3+}$ concentration; and is a constant for the same excitation condition for a given host. $\theta=6,8$, or 10 for dipole-dipole $(\mathrm{d}-\mathrm{d})$, dipole-quadrupole $(\mathrm{d}-\mathrm{q})$ and quadrupolequadrupole $(\mathrm{q}-\mathrm{q})$, respectively. For the phosphor CZGO:Dy ${ }^{3+}$, the dependence of $\log \left(I / x_{\mathrm{Dy}^{3+}}\right)$ on $\log \left(x_{\mathrm{Dy}^{3+}}\right)$ shown in Fig. 12 is almost linear and the fitted line slopes are -1.44 and -1.49 for ${ }^{4} \mathrm{~F}_{9 / 2} \rightarrow{ }^{6} \mathrm{H}_{13 / 2}$ and ${ }^{4} \mathrm{~F}_{9 / 2} \rightarrow{ }^{6} \mathrm{H}_{15 / 2}$ transition respectively. The value of $\theta$ is 6 determined by the line slope, indicating the electric $\mathrm{d}-\mathrm{d}$ interaction is responsible for the concentration quenching of $\mathrm{Dy}^{3+}$ ions in CZGO.

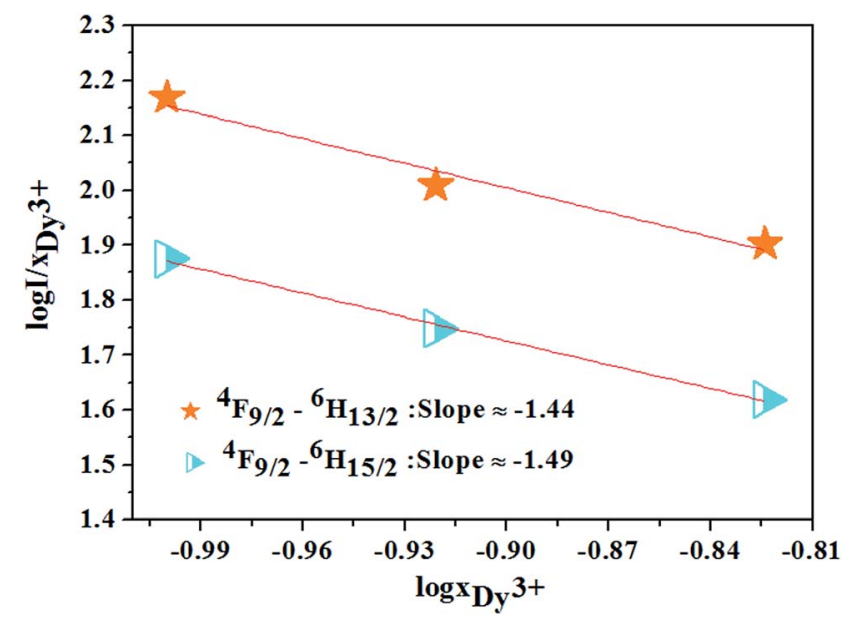

Fig. 12 The relations of $\log \left(/ / x_{\mathrm{Dy}^{3+}}\right)$ and $\log \left(x_{\mathrm{Dy}^{3+}}\right)$ for ${ }^{4} \mathrm{~F}_{9 / 2} \rightarrow{ }^{6} \mathrm{H}_{13 / 2}$, ${ }^{4} \mathrm{~F}_{9 / 2} \rightarrow{ }^{6} \mathrm{H}_{15 / 2}$ transitions of Dy ${ }^{3+}$ ions.

\subsection{Optimized white light of CAGO:Dy ${ }^{3+}, \mathrm{Mn}^{4+}$}

Fig. 13 shows PL spectra of $\mathrm{Ca}_{13.9} \mathrm{Zn}_{6} \mathrm{Ga}_{10-y} \mathrm{O}_{35}: 0.1 \mathrm{Dy}^{3+}, y \mathrm{Mn}^{4+}$ phosphors $(y=0.03,0.09,0.12,0.15,0.20,0.25)$ at room temperature $\left(\lambda_{\text {ex }}=266 \mathrm{~nm}\right)$. The spectra exhibits blue CTB, blue/yellow emissions and a deep red emission, which result from the emission of host, ${ }^{4} \mathrm{~F}_{9 / 2} \rightarrow{ }^{6} \mathrm{H}_{15 / 2} /{ }^{4} \mathrm{~F}_{9 / 2} \rightarrow{ }^{6} \mathrm{H}_{13 / 2}$ transitions of $\mathrm{Dy}^{3+}$ ion and ${ }^{2} \mathrm{E} \rightarrow{ }^{4} \mathrm{~A}_{2}$ transition of $\mathrm{Mn}^{4+}$ ion, respectively. As $\mathrm{Mn}^{4+}$ concentration increases, the emissions intensity of both host and $\mathrm{Dy}^{3+}$ ions decrease, and the maximum emission of $\mathrm{Mn}^{4+}$ ions is shown as $y=0.15$. As discussed above, energy transfer exists from host to $\mathrm{Dy}^{3+}$ ions at the excitation of $266 \mathrm{~nm}$. Moreover, the external QEs of $\mathrm{Mn}^{4+}$ ion excited at $266 \mathrm{~nm}$ in $\mathrm{Ca}_{13.9} \mathrm{Zn}_{6} \mathrm{Ga}_{9.85} \mathrm{O}_{35}: 0.1 \mathrm{Dy}^{3+}, 0.15 \mathrm{Mn}^{4+}$ and $\mathrm{Ca}_{14} \mathrm{Zn}_{6} \mathrm{Ga}_{9.85} \mathrm{O}_{35}: 0.15 \mathrm{Mn}^{4+}$ are measured as $15.6 \%$ and $10.1 \%$, which indicating the energy transfer from $\mathrm{Dy}^{3+}$ to $\mathrm{Mn}^{4+}$ helps enhancing the QEs of $\mathrm{Mn}^{4+}$ emission. Energy transfer from $\mathrm{Dy}^{3+}$ to $\mathrm{Mn}^{4+}$ ions is also possible due to the overlap between the PLE spectrum of $\mathrm{Mn}^{4+}$ ions and PL spectrum of $\mathrm{Dy}^{3+}$ ions in CAG$\mathrm{O}: \mathrm{Dy}^{3+}, \mathrm{Mn}^{4+}$. The energy transfer mechanism from $\mathrm{Dy}^{3+}$ to $\mathrm{Mn}^{4+}$ ion can be explained as non-radiative transitions from ${ }^{4} \mathrm{~F}_{9 /}$ ${ }_{2}$ level of $\mathrm{Dy}^{3+}\left(20747 \mathrm{~cm}^{-1}\right)$ to ${ }^{4} \mathrm{~T}_{2}$ level of $\mathrm{Mn}^{4+}\left(14025 \mathrm{~cm}^{-1}\right)$ by the assistance of phonons ${ }^{48}$ by Fig. 10 . Therefore, multiply energy transfer can be happen in CZGO:Dy ${ }^{3+}, \mathrm{Mn}^{4+}$ at the excitation of $266 \mathrm{~nm}$.

Fig. 14(a) shows the luminescence decay curves (excited at $266 \mathrm{~nm}$ and monitored at $486 \mathrm{~nm}$ of $\mathrm{Dy}^{3+}$ emission) of $\mathrm{Ca}_{13.9^{-}}$ $\mathrm{Zn}_{6} \mathrm{Ga}_{10-y} \mathrm{O}_{35}: 0.1 \mathrm{Dy}^{3+}, y \mathrm{Mn}^{4+}$ samples. The lifetimes were determined by the fitting of single exponential function to be $0.630,0.468,0.360,0.334,0.316,0.296$ and $0.261 \mathrm{~ms}$ for $y=0$, $0.03,0.09,0.12,0.15,0.20$, and 0.25 respectively, shown also in Fig. 14(a). The decrease of the lifetime confirms the existence of energy transfer from $\mathrm{Dy}^{3+}$ to $\mathrm{Mn}^{4+}$. The energy-transfer efficiency $\eta_{T}$ is calculated using eqn (5) and shown in Fig. 14(b). Although the value of $\eta_{T}$ always increase with increasing $\mathrm{Mn}^{4+}$ dopant concentration in our experiment, the emission intensity of $\mathrm{Mn}^{4+}$ tends to decrease at higher $\mathrm{Mn}^{4+}$ concentration $(x>$ $0.15)$ due to the concentration quenching. The energy transfer efficiency is $59 \%$ when $y=0.25$ with maximal $713 \mathrm{~nm}$ emission intensity.

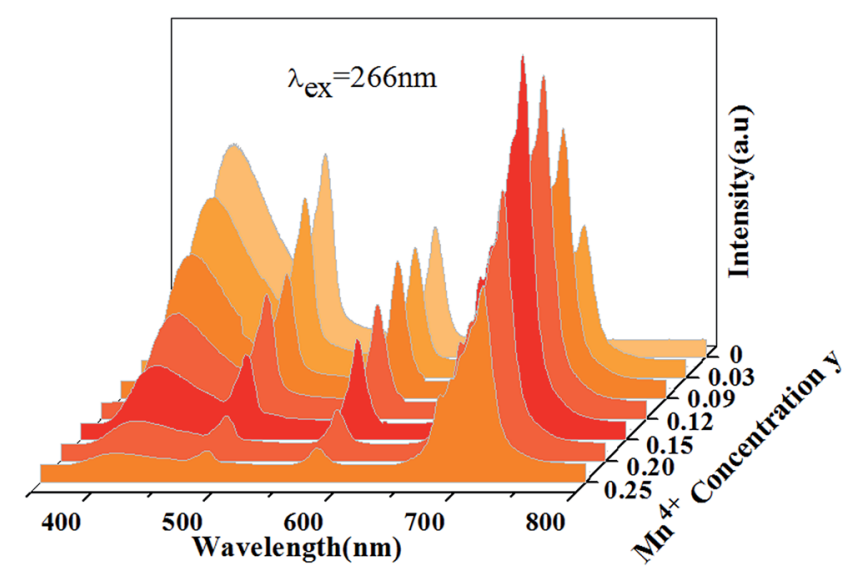

Fig. 13 Photoluminescence emission spectra of $\mathrm{Ca}_{13.9} \mathrm{Zn}_{6} \mathrm{Ga}_{10-y^{-}}$ $\mathrm{O}_{35}: 0.1 \mathrm{Dy}^{3+}, \mathrm{yMn}^{4+}$ as a function of $y$ under $\lambda_{\mathrm{ex}}=266 \mathrm{~nm}$. 
(a)
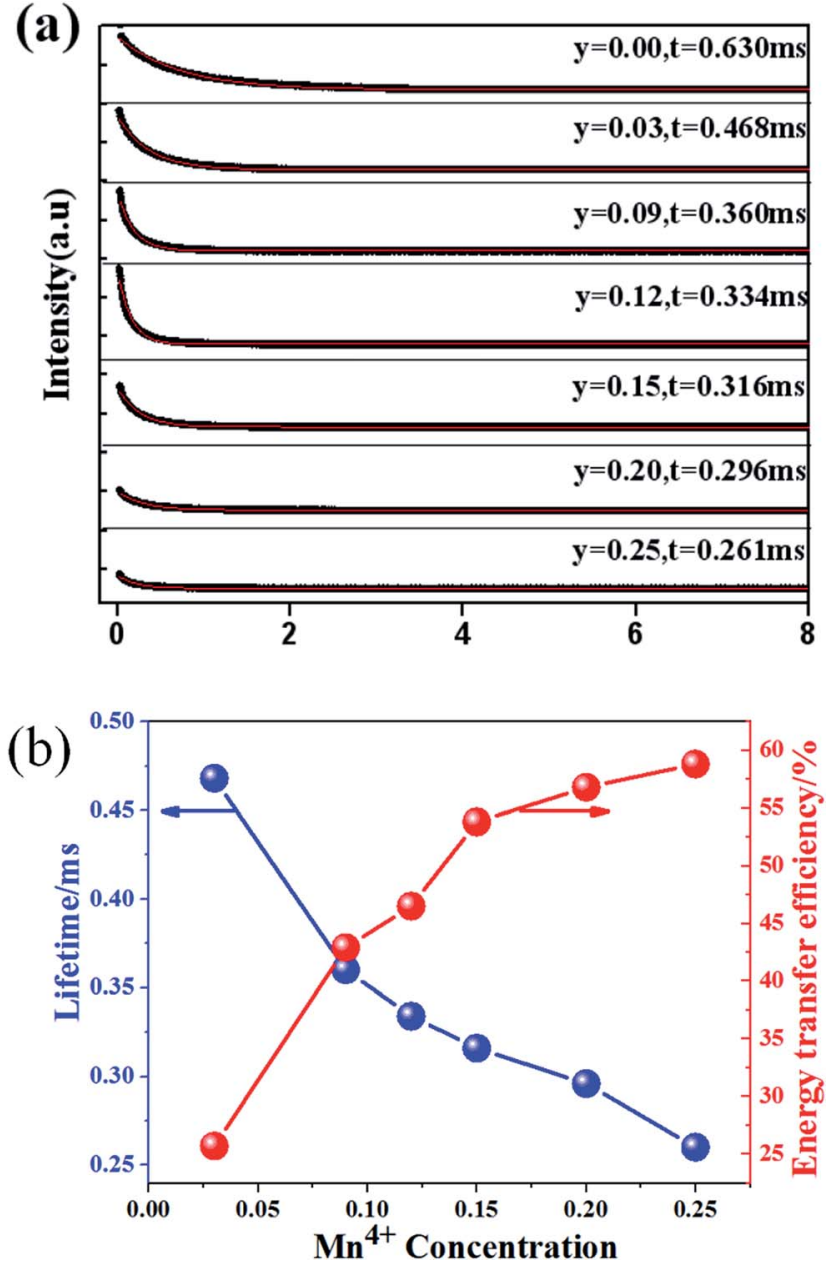

Fig. 14 (a) Decay curves of $\mathrm{Ca}_{13.9} \mathrm{Zn}_{6} \mathrm{Ga}_{10-y} \mathrm{O}_{35}: 0.1 \mathrm{Dy}^{3+}, y \mathrm{Mn}^{4+}$ phosphors doped with various $\mathrm{Mn}^{4+}$ concentrations (excited at $266 \mathrm{~nm}$ and monitored at $486 \mathrm{~nm}$ ). (b) The dependence of lifetime and energy transfer efficiency (corresponding to the Dy ${ }^{3+}{ }^{4} \mathrm{~F}_{9 / 2} \rightarrow{ }^{6} \mathrm{H}_{15 / 2}$ transition) in $\mathrm{Ca}_{13.9} \mathrm{Zn}_{6} \mathrm{Ga}_{10-y} \mathrm{O}_{35}: 0.1 \mathrm{Dy}^{3+}, \mathrm{yMn}^{4+}(y=0.05,0.09,0.12$, $0.15,0.20,0.25)$ on $\mathrm{Mn}^{4+}$ concentration.

According to Dexter's energy-transfer model of multipolar interaction and Reisfeld's approximation, the following relation can be given ${ }^{49,50}$

$$
\frac{\tau_{\mathrm{Dy}}}{\tau_{\mathrm{Dy}-\mathrm{Mn}}} \propto C^{S / 3}
$$

where $\tau_{\mathrm{Dy}}$ and $\tau_{\mathrm{Dy}-\mathrm{Mn}}$ are the lifetimes of $\mathrm{Dy}^{3+}$ in the absence and presence of $\mathrm{Mn}^{4+}$, respectively. $C$ is the sum of the concentrations of $\mathrm{Dy}^{3+}$ and $\mathrm{Mn}^{4+}$, and $S=6,8$ and 10 corresponding to d$\mathrm{d}, \mathrm{d}-\mathrm{q}$, and $\mathrm{q}-\mathrm{q}$ interactions, respectively. Fig. 15 shows the linear fitting of the relationship between $\tau_{\mathrm{Dy}} / \tau_{\mathrm{Dy}-\mathrm{Mn}}$ and $C^{S / 3}$, and the largest values of $R^{2}$ with $S=6$, indicating that the energy transfer from $\mathrm{Dy}^{3+}$ to $\mathrm{Mn}^{4+}$ occurs via $\mathrm{d}$-d interaction.

Fig. 16 shows the CIE chromaticity diagram of (a) CZGO, (b) $\mathrm{Ca}_{13.9} \mathrm{Zn}_{6} \mathrm{Ga}_{10} \mathrm{O}_{35}: 0.1 \mathrm{Dy}^{3+}$, (c) $\mathrm{Ca}_{13.9} \mathrm{Zn}_{6} \mathrm{Ga}_{9.85} \mathrm{O}_{35}: 0.1 \mathrm{Dy}^{3+}, 0.15 \mathrm{Mn}^{4+}$ excited at $266 \mathrm{~nm}$ and (d) $\mathrm{Ca}_{14} \mathrm{Zn}_{6} \mathrm{Ga}_{9.85} \mathrm{O}_{35}: 0.15 \mathrm{Mn}^{4+}$ excited at $310 \mathrm{~nm}$. The phosphor CZGO emits deep blue light, of which the chromaticity coordinate is $(0.158,0.062)$. The chromaticity coordinates of $\mathrm{Ca}_{13.9} \mathrm{Zn}_{6} \mathrm{Ga}_{10} \mathrm{O}_{35}: 0.1 \mathrm{Dy}^{3+}$ and $\mathrm{Ca}_{13.9} \mathrm{Zn}_{6} \mathrm{Ga}_{9.85}$

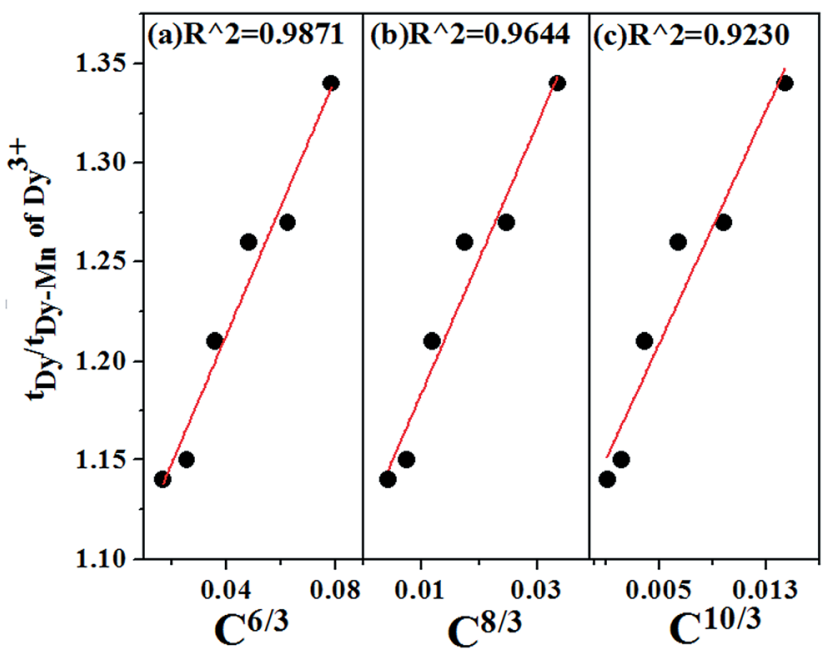

Fig. 15 Dependence of $\tau_{\mathrm{Dy}} / \tau_{\mathrm{Dy}-\mathrm{Mn}}$ on (a) $C^{6 / 3}$, (b) $C^{8 / 3}$ and (c) $C^{10 / 3} \mathrm{in}$ $\mathrm{Ca}_{13.9} \mathrm{Zn}_{6} \mathrm{Ga}_{10-y} \mathrm{O}_{35}: 0.1 \mathrm{Dy}^{3+}, \mathrm{yMn}^{4+}(y=0.05,0.09,0.12,0.15,0.20$, $0.25)$. The best linear fitting indicates the energy transfer from $\mathrm{Dy}^{3+}$ to $\mathrm{Mn}^{4+}$ occurs via $\mathrm{d}-\mathrm{d}$ interaction.

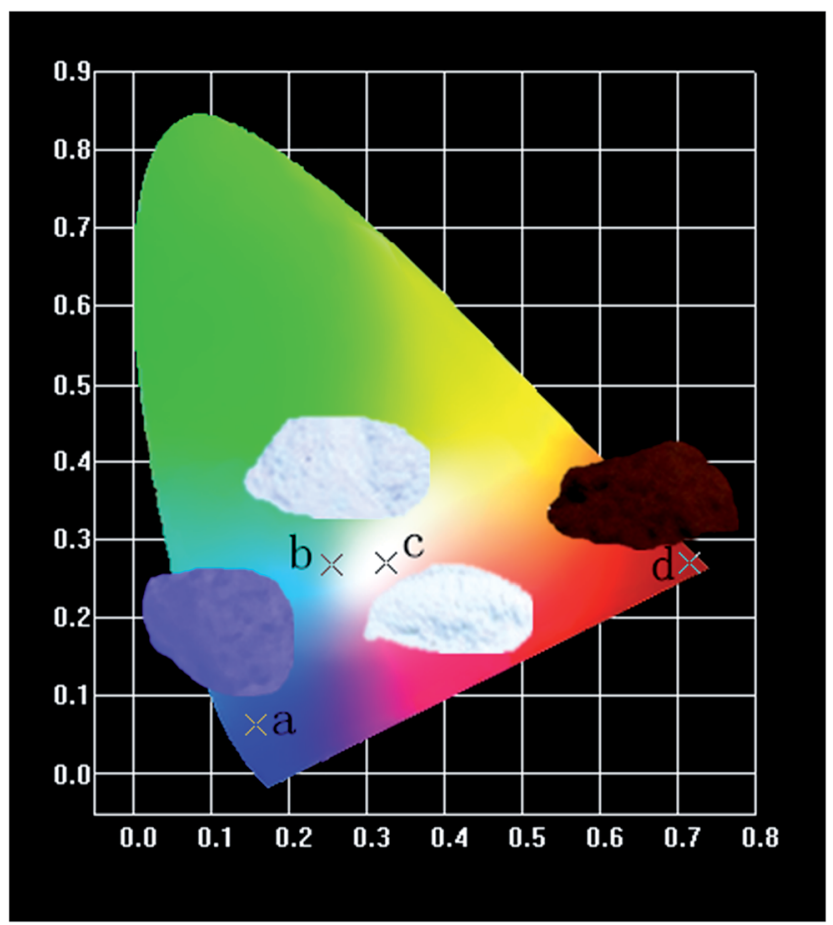

Fig. $16 \mathrm{CIE}$ chromaticity coordinates of (a) CZGO, (b) $\mathrm{Ca}_{13.9} \mathrm{Zn}_{6^{-}}$ $\mathrm{Ga}_{10} \mathrm{O}_{35}: 0.1 \mathrm{Dy}^{3+}$, (c) $\mathrm{Ca}_{13.9} \mathrm{Zn}_{6} \mathrm{Ga}_{9.85} \mathrm{O}_{35}: 0.1 \mathrm{Dy}^{3+}, 0.15 \mathrm{Mn}^{4+}$ excited at $266 \mathrm{~nm}$ and (d) $\mathrm{Ca}_{14} \mathrm{Zn}_{6} \mathrm{Ga}_{9.85} \mathrm{O}_{35}: 0.15 \mathrm{Mn}^{4+}$ excited at $310 \mathrm{~nm}$ in wavelength range $380-800 \mathrm{~nm}$.

$\mathrm{O}_{35}: 0.1 \mathrm{Dy}^{3+}, 0.15 \mathrm{Mn}^{4+}$ with CCTs of $5252 \mathrm{~K}$ and $3522 \mathrm{~K}$, with CRIs of 72 and 87 , are $(0.254,0.288)$ and $(0.345,0.275)$, respectively. Obviously, higher color rendering index (CRI) and lower color temperature are obtained by adding $\mathrm{Mn}^{4+}$ ions. Except for the short exciting wavelength, the high color rendering index $\left(R_{\mathrm{a}}=87\right)$ and low color temperature $3522 \mathrm{~K}$ can well meet the generally lighting. 


\section{Conclusion}

In summary, strong blue emission band ranging from $370 \mathrm{~nm}$ to $500 \mathrm{~nm}$ was observed for CZGO host, attributed to the recombination of a donor-acceptor pair (DAP) through a tunneling process. The highest internal and external quantum efficiencies were measured to be $64.4 \%$ and $56.2 \%$ respectively for CZGO: $\mathrm{Mn}^{4+}$. This external quantum efficiency is the highest one reported for $\mathrm{Mn}^{4+}$ doped oxides. The energy transfer processes either from the host to $\mathrm{Dy}^{3+}$ or from $\mathrm{Dy}^{3+}$ to $\mathrm{Mn}^{4+}$ are confirmed and demonstrated arising from dipole-dipole interaction in $\mathrm{Dy}^{3+} / \mathrm{Mn}^{4+}$ co-doped CZGO, and the emission changes from deep blue to white to deep red according to the different $\mathrm{Dy}^{3+} / \mathrm{Mn}^{4+}$ concentration ratio, and Furthermore, the warm white emission can be realized with the chromaticity coordinate $(0.345,0.275)$, CCT $3525 \mathrm{~K}$ and CRI 87. The results suggest CZGO: $\mathrm{Mn}^{4+}$ phosphors have the potential application as high efficiency red phosphors for solid-state lighting, while $\mathrm{Dy}^{3+} / \mathrm{Mn}^{4+}$ co-doped CZGO can used as a single-phased white phosphor.

\section{Acknowledgements}

Financial supported from the Key Laboratory of Innovation Method and Decision Management System of Guangdong Province, the Research Guangzhou Science (No. 2016201604030035) and Technology Project of Guangdong Province, China (No. 2016201604030027).

\section{References}

1 J. H. Chen, W. R. Zhao, N. H. Wang, Y. J. Meng, S. P. Yi, J. He and X. Zhang, J. Mater. Sci., 2016, 51, 4201-4212.

2 Y. H. Jin, Y. R. Fu, Y. H. Hu, L. Chen, H. Y. Wu, G. F. Ju, M. He and T. Wang, Powder Technol., 2016, 292, 74-79.

3 T. Murata, T. Tanoue, M. Iwasaki, K. Morinaga and T. Hase, J. Lumin., 2005, 114, 207-212.

4 M. G. Brik, Y. X. Pan and G. K. Liu, J. Alloys Compd., 2011, 509, 1452-1456.

5 A. A. Setlur, E. V. Radkov, C. S. Henderson, J.-H. Her, A. M. Srivastava, N. Karkada, M. S. Kishore, N. P. Kumar, D. A. Esram, A. Deshpande, B. Kolodin, L. S. Grigorov and U. Happek, Chem. Mater., 2010, 2, 4076-4082.

6 G. B. Loutts, M. Warren, L. Taylor, R. R. Rakhimov, H. R. Ries, G. Miller III, M. A. Curley, N. Noginova, N. Kukhtarev, H. J. Caulfeld and P. Venkateswarlu, Phys. Rev. B: Condens. Matter Mater. Phys., 1998, 57, 3706.

7 Y. Zhydachevskii, D. Galanciak, S. Kobyakov, M. Berkowski, A. Kaminska, A. Suchocki, Y. Zakharko and A. Durygin, J. Phys.: Condens. Matter, 2006, 18, 11385-11396.

8 Y. Zhydachevskii, A. Durygin, A. Suchocki, A. Matkovskii, D. Sugak, P. Bilski and S. Warchol, Nucl. Instrum. Methods Phys. Res., Sect. B, 2005, 227, 545-550.

9 T. Arai and S. Adachi, Jpn. J. Appl. Phys., 2011, 50, 092401.

10 H. M. Zhu, C. C. Lin, W. Q. Luo, S. T. Shu, Z. G. Liu, Y. S. Liu, J. T. Kong, E. Ma, Y. G. Cao, R. S. Liu and X. Y. Chen, Nat. Commun., 2014, 5, 4312.
11 T. Takahashi and S. Adachi, J. Electrochem. Soc., 2008, 155, 183-188.

12 M. H. Du, J. Mater. Chem. C, 2014, 2, 2475.

13 M. G. Brik and A. M. Srivastava, J. Lumin., 2013, 133, 69-72.

14 M. Y. Peng, X. W. Yin, P. A. Tanner, C. Q. Liang, P. F. Li, Q. Y. Zhang and J. R. Qiu, J. Am. Ceram. Soc., 2013, 96, 2870-2876.

15 L. Wang, L. Yuan, Y. Xu, R. Zhu, B. Y. Qu, N. Ding, M. Shi, B. Zhang, Y. Chen, Y. Jiang, D. Wang and J. Shi, Appl. Phys. A, 2014, 117, 1777-1783.

16 B. Wang, H. Lin, J. Xu, H. Chen and Y. Wang, ACS Appl. Mater. Interfaces, 2014, 6, 22905-22913.

17 R. Cao, M. Peng, E. Song and J. Qiu, ECS J. Solid State Sci. Technol., 2012, 1, 123-126.

18 K. Seki, K. Uematsu, K. Toda and M. Sato, Chem. Lett., 2014, 43, 1213-1215.

19 X. Y. Sun, M. Gu, S. M. Huang, X. L. Liu, B. Liu and C. Ni, Phys. B, 2009, 404, 111-114.

$20 \mathrm{~S}$. Y. Istomin, S. V. Chernov, E. V. Antipov and Yu. A. Dobrovolsky, J. Solid State Chem., 2007, 180, 18821888.

21 I. D. Brown, The Chemical Bond in Inorganic Chemistry. The Bond Valence Model, IUCr Monographs on Crystallography, Oxford University Press, 2002.

22 R. D. Shannon, Acta Crystallogr., Sect. A: Cryst. Phys., Diffr., Theor. Gen. Crystallogr., 1976, 32, 751-767.

23 Y. E. Lee, D. P. Norta, C. Park and C. M. Roulean, J. Appl. Phys., 2001, 89, 1653-1655.

24 K. W. Chang and J. J. Wu, J. Phys. Chem. B, 2005, 109, 1357213577.

25 L. E. Shea, R. K. Datta and J. J. Brown Jr, J. Electrochem. Soc., 1994, 141, 1950-1954.

26 I. K. Jeong, H. L. Park and S. I. Mho, Solid State Commun., 1998, 105, 179-183.

27 J. S. Kim, H. I. Kang, W. Kim, N. J. I. Kim, J. C. Choi, H. L. Park, G. C. Kim, T. W. Kim, Y. H. Hwang, S. I. Mho, M. C. Jung and M. Han, Appl. Phys. Lett., 2003, 82, 2029-2042.

28 A. M. Srivastava and W. W. Beers, J. Electrochem. Soc., 1996, 143, L203-L205.

29 Y. Tanabe and S. Sugano, J. Phys. Soc. Jpn., 1954, 9, 766-779. 30 M. J. Reisfeld, N. A. Matwiyof and L. B. Aspery, J. Mol. Spectrosc., 1971, 39, 8-20.

31 B. Henderson and G. F. Imbusch, Optical Spectroscopy of Inorganic Solids, Clarendon Press, Oxford, UK, 1984.

32 M. G. Brik and A. M. Srivastava, ECS J. Solid State Sci. Technol., 2013, 2, 148-152.

33 Y. H. Jin, T. H. Hu, H. Y. Wu, H. Duan, L. Chen, Y. R. Fu, D. F. Ju, Z. F. Mu and M. He, Chem. Eng. J., 2016, 288, 596-607.

34 P. Uylings, A. Raassen and J. Wyart, J. Phys. B: At. Mol. Phys., 1984, 17, 4103-4126.

35 M. G. Brik and A. M. Srivastava, Ion in Solids, J. Lumin., 2013, 133, 69-72.

36 V. Bachmann, A. Meijerink and C. Ronda, J. Lumin., 2009, 129, 1341-1346.

37 Z. G. Xia and R. S. Liu, J. Phys. Chem. C, 2012, 116, 1560415609.

38 Y. P. Varshni, Physica, 1967, 34, 149-154. 
39 J. S. Kim, Y. H. Park, S. M. Kim, J. C. Choi and H. L. Park, Solid State Commun., 2005, 133, 445-448.

40 Y. L. Huang, J. H. Gana, R. Zhua, X. G. Wang and H. J. Seo, J. Electrochem. Soc., 2011, 158, 334-J340.

41 W. R. Wang, A. F. Zou, X. Lei, H. P. Gao and Y. L. Mao, Opt. Mater., 2014, 38, 261-264.

42 Q. Y. Zhang and C. F. Yang, Appl. Phys. Lett., 2007, 91, 051903.

43 P. I. Paulose, G. Jose, V. Thomas, N. V. Unnikrishnan and M. K. R. Warrier, J. Phys. Chem. Solids, 2003, 64, 841-846.

44 I. R. Martín, V. D. Rodríguez, U. R. Rodríguez-Mendoza, V. Lavín, E. Montoya and D. Jaque, J. Chem. Phys., 1999, 111, 1191.
45 G. Blasse, Phys. Lett. A, 1968, 28, 444-445.

46 G. Blasse, Philips Res. Rep., 1969, 24, 131.

47 D. L. Dexter and J. H. Schulman, J. Chem. Phys., 1954, 22, 1063-1069.

48 Z. Xia, Y. Zhang, M. S. Molokeev and V. V. Atuchin, J. Phys. Chem. C, 2013, 117, 20847-20854.

49 D. L. Dexter and J. H. Schulman, J. Chem. Phys., 1954, 22, 1063-1070.

50 R. Reisfeld and N. L. Soffer, J. Solid State Chem., 1979, 28, 391-395. 